DEMOGRAPHIC RESEARCH

VOLUME 40, ARTICLE 10, PAGES 261-278

PUBLISHED 30 JANUARY 2019

http://www.demographic-research.org/Volumes/Vol40/10/

DOI: $10.4054 /$ DemRes.2019.40.10

Research Article

\title{
Identifying interaction effects using random fertility shocks
}

\section{Rannveig Kaldager Hart}

\section{Sara Cools}

(c) 2019 Rannveig Kaldager Hart \& Sara Cools.

This open-access work is published under the terms of the Creative Commons Attribution 3.0 Germany (CC BY 3.0 DE), which permits use, reproduction, and distribution in any medium, provided the original author(s) and source are given credit.

See https://creativecommons.org/licenses/by/3.0/de/legalcode 


\section{Contents}

$\begin{array}{lll}1 & \text { Introduction } & 262\end{array}$

2 Mechanisms for fertility interaction effects $\quad 263$

$3 \quad$ Empirical approach $\quad 265$

$\begin{array}{lll}3.1 & \text { Data } & 265\end{array}$

$\begin{array}{lll}3.2 & \text { Identification strategy } & 265\end{array}$

$4 \quad$ Results $\quad 267$

$\begin{array}{lll}4.1 & \text { Descriptive statistics and balancing tests } & 267\end{array}$

$\begin{array}{ll}4.2 & \text { Sibship sex composition as IV } \\ 4.3 & 269\end{array}$

$\begin{array}{lll}4.3 & \text { Twinning as IV } & 271\end{array}$

$\begin{array}{lll}4.4 & \text { Subsample analysis } & 273\end{array}$

5 Concluding discussion $\quad 273$

$\begin{array}{ll}\text { References } & 275\end{array}$ 


\title{
Identifying interaction effects using random fertility shocks
}

\author{
Rannveig Kaldager Hart ${ }^{1}$ \\ Sara Cools ${ }^{2}$
}

\begin{abstract}
BACKGROUND

Fertility interaction effects in social networks increasingly attracts the interest of demographers. While these theories propose a causal mechanism, they are rarely put to test in a plausibly causal statistical design.
\end{abstract}

\section{OBJECTIVE}

We aim to differentiate network effects from selection by using an instrumental variable (IV) approach to achieve exogenous variation in fertility. We use interaction effects between siblings as an empirical example.

\section{METHODS}

We draw data from Norwegian administrative registers $(\mathrm{N} \sim 170,000$ men and women). We use twin births and children's sex composition as random fertility shocks (IVs), generating exogenous variation in third births.

\section{RESULTS}

In our full study sample, we find no significant effects on ego's fertility of random shocks to the propensity to have three children. Subgroup analysis by sex and parity indicates positive effects for firstborn women when the sibling's birth is intended (as captured by the same-sex instrument). We find no evidence that similarity strengthens interaction effects.

\section{CONCLUSIONS}

The study contributes to the literature by testing long-standing hypotheses of fertility interaction effects in a plausibly causal design. With the exception of firstborn women, we find no evidence of interaction effects of a sibling's third birth.

\footnotetext{
${ }^{1}$ Department of Health and Inequality, Norwegian Institute of Public Health and Research Department, Statistics Norway, Oslo, Norway. Email: rannveigkaldager.hart@fhi.no.

${ }^{2}$ Institutt for samfunnsforskning (Institute for Social Research), Oslo, Norway. Email: sara.cools@samfunnsforskning.no.
} 
Hart \& Cools: Identifying interaction effects using random fertility shocks

\section{Introduction}

One individual's fertility behavior may affect that of others, and when friends and family have children, one's own preferences and knowledge regarding life with children may change. These interaction effects are typically expected to be stronger between individuals who are relatively similar and who keep in frequent contact (Bernardi and Klaerner 2014).

Existing studies show positive correlations in fertility timing among colleagues (Pink, Leopold, and Engelhardt 2014), friends (Balbo and Barban 2014; Lois and Becker 2014), and siblings (Kuziemko (2006) and Lyngstad and Prskawetz (2010), but see Kotte and Ludwig (2011) for a counterexample). However, these correlations are potentially biased as estimates of network effects, due to common unobservable characteristics, reflection, and - in the case of friends and colleagues - endogenous group membership (Dahl, Løken, and Mogstad 2014; Manski 1995).

In this study we aim to estimate fertility interaction effects in sibling networks, using random variation in fertility to obtain causal estimates without such bias. We use data on fertility behavior from Norwegian administrative registers $(\mathrm{N} \sim 170,000)$. Because siblings usually keep in contact throughout adulthood and are often relatively similar, we expect them to impact each other's fertility. However, we also expect them to share underlying characteristics (such as fertility preferences) that cannot be perfectly measured and netted out by the researcher. Our method for handling this endogeneity is to use random shocks to the sibling's fertility. To the best of our knowledge, using exogenous variation to identify interaction effects has previously been done only for teenage fertility, suggesting both negative (Yakusheva and Fletcher 2015) and positive (Monstad, Propper, and Salvanes 2011) effects.

Two types of fertility shocks are used extensively in the demographic and economic literature: twin births and children's sex composition. A twin birth is an unintended family increase, demonstrably random, conditional on the parents' age (Rosenzweig and Wolpin 1980a,b; Black, Devereux, and Salvanes 2005). Having two children of the same sex is also random, and it increases parents' probability of having a third child (Gini 2014; Angrist and Evans 1998).

The two instrumental variables (IVs) both concern the propensity to have a third child and restrict us to estimating effects running from a sibling's third birth to ego's birth at any parity. There are several reasons to explore the interaction effects arising from third births in the Norwegian context. Childlessness is low among women, and more than $80 \%$ of mothers have a second child (Rønsen 2004). In contrast, the transition to a third child is far less frequent (ibid.). Third births are related to persistent career costs for women (Cools, Markussen, and Strøm 2017) and to wage penalties in later years, even for men (Cools and Strøm 2017). The third parity transition may therefore be the most uncertain one, and the one where individuals rely on their network for information 
and support to the largest extent. Previous studies have generally found first births to be correlated with fertility in the social network (Balbo and Barban 2014; Bernardi 2003; Lyngstad and Prskawetz 2010). In a separate contribution of this paper, we show in ordinary least squares (OLS) estimates that siblings' third births are indeed correlated with ego's fertility choices, in the same way that the existing literature has found earlier births to be empirically relevant.

The two IVs concern rather different fertility experiences. Having twins at second birth is likely to be more straining than having a third child due to a wish for children of both sexes. First, there is no spacing between twins. If shorter spacing makes the family increase seem more stressful, the interaction effects due to twinning ought to be less positive than those resulting from the average third birth. Interaction effects could then be comparable to effects from third births that are straining for other reasons, such as health problems in mother or child. Second, the twin instrument captures the effect of a third birth among couples who would otherwise prefer to have only two children, whereas the same-sex instrument captures the effect of a third birth among parents who would stop at two children if - and only if - they were of opposite sex. We explore the different nature of these shocks to see how they matter for interaction effects.

\section{Mechanisms for fertility interaction effects}

For interaction effects related to first births, three types of mechanisms have traditionally been considered of importance: social learning, emotional contagion, and social pressure. When the concern is interaction effects arising specifically from third births, the relative importance of these mechanisms may change. We expect effects from third births to mainly concern quantum - the intention to have a large family. Changes in quantum preferences may in turn affect the timing of first or second births.

In the Norwegian context, wanting at least two children seems a 'default option': More than $80 \%$ of young childless Norwegians intend to have a child (Lyngstad and Noack 2005). Analysis of recently collected Norwegian survey data show that among women who want children, more than $92 \%$ want at least two. Out of these, less than half (42\%) want at least three (own calculations, see Cools and Strøm (2018) for a description of the data set). The variation over time in the proportion who proceed to have a third child closely follows the fluctuation in overall fertility (Cools 2013), and is suggested to be a major driver of the 'second demographic transition' in Norway (Kravdal 1992). Various recent studies have identified the decline in third births as a main driver of the observed decline in Norwegian fertility since 2009 (Cools and Strøm 2018; Dommermuth and Lappegård 2017).

Research from related fields supports the notion that the propensity to have three children is correlated within networks. Three-child families are found to be clustered in 
Hart \& Cools: Identifying interaction effects using random fertility shocks

space (see Fiori, Graham, and Feng (2014) for Britain, Gray and Evans (2014) for Australia, Bergsvik, Lappegård, and Skardhamar (2016) for Norway), indicating geographic self-selection based on preferences for family size, and/or neighborhood interaction effects for the propensity to have a third child. Similarly, parity-specific analyses reveal that third births also correlate across generations (Cools and Hart 2017), and there is also some evidence that this positive relationship is causal for men (ibid.).

Even for individuals who have seen their sibling have a first and then a second child, new information of life in large families may be revealed when a third niece or nephew is born, and individuals observe how family life changes with the shift from a 'standard size' family to 'large' family. Perhaps the most striking effect of a third child is its significant negative effect on the mother's earnings (Cools, Markussen, and Strøm 2017), which may amplify both career frustrations and income concerns. There is also some evidence that a third child, as instrumented by twinning and/or sex composition, has a negative impact on the mother's health in the short (Cáceres-Delpiano and Simonsen 2012) and long run (Kruk and Reinhold 2014). Furthermore, as many medium-sized Norwegian family homes have three bedrooms, housing considerations become pertinent. Also, a third child is likely to change both sibling dynamics and parent-child interactions due a larger age span between the children and the outnumbering of their parents. Last, theories based on evolutionary psychology have suggested that the mere exposure to babies - even for women who are already mothers - may induce a "baby longing," and hence increase fertility (Rotkirch 2007).

Together, these examples illustrate that the birth of a third child within the social network can be a source of both social learning and emotional contagion, particularly for couples pondering whether to have a third child. Given that several grandchildren are already present, social pressure (from grandparents) is presumably of lesser importance at this margin. It is possible that the further expansion of a sibling's family further dilutes social support in terms of grandparental resources, perhaps contributing marginally to a negative interaction effect. Hence, we argue that there is potential for both positive and negative interaction effects of a sibling's third birth on ego's fertility. The effects may be corroborated by families with three children being rarer than families with two children, heightening the informational value of an "up close" observation of the transition from two to three children compared with the earlier parities.

Depending on how both ego and the sibling perceive the fertility shock, the effect on ego's fertility may be positive or negative. As twin births are both more straining and unplanned (unintended births are on average linked to adverse outcomes for children and parents (Abajobir et al. 2016; Barber and East 2009; David 2006; Myhrman et al. 1995)), we expect them to transmit less positively than third births induced by sex mix preferences.

Mechanisms for transmission are likely to depend on network characteristics. For social learning or belief formation, similarity is crucial (Bernardi 2003; Pink, Leopold, 
and Engelhardt 2014). As childbearing in general (and third births in particular) influences men's and women's lives differently, we expect siblings of the same sex to be more influential (see Bernardi (2003) for an empirical example). Interaction effects of third births may also be stronger at certain parities: Childless individuals may be more easily influenced by their peers (Bernardi 2003), or a sibling's third birth may convey specific information about this family size, mainly relevant for ego's decision regarding a third child.

Finally, older siblings may influence younger siblings more than the other way around: As the older child experiences most transitions first, the younger siblings may grow used to using their older siblings as role models in childhood and continue to do so in adulthood.

\section{Empirical approach}

\subsection{Data}

All data come from administrative registers. Personal identification numbers link individuals to their siblings, parents, and children. Our two IVs - the sex mix of the sibling's first two children and whether the sibling had twins at second birth - both move the sibling's number of children from two to more than two children and are defined only for siblings who have at least two children. Therefore, our study sample consists of men and women whose sibling had a second child in the period 1980-1999. The sample is not conditioned on ego's childbearing history. In order to have well-defined sibling relations, we restrict the sample to firstborn and secondborn men and women. We exclude individuals whose sibling had twins at first birth.

To obtain consistent IV estimates, we include only control variables that are not themselves influenced by the instrument (i.e., that are determined prior to or at the realization of the instrument). This limits the number of suitable controls available in the data. We include controls for the calendar year of a sibling's second birth, the age difference between ego and sibling, and the age difference between the sibling's two firstborn children as yearly dummies. In addition, we control for the sibling's and the sibling's partner's age at second birth by dummies for five-year age brackets.

\subsection{Identification strategy}

Without exogenous variation in fertility, the estimation of interaction effects among siblings is likely to be biased due to common unobservable characteristics and reflection (Manski 1995). For this reason we use two IVs for the sibling's number of children. A valid IV must increase the sibling's fertility but cannot be correlated with any (un- 
Hart \& Cools: Identifying interaction effects using random fertility shocks

observed) characteristics that could cause ego's and sibling's childbearing patterns to be related.

While both instruments are extensively used in estimating the effect of family size on other outcomes, application to fertility outcomes remains rare (exceptions are Cools and Hart (2017) and Kolk (2015)). In our sample, a sibling's twinning at second birth on average increases their probability of having a third child by about $57 \%$ (reflecting that about $43 \%$ of parents with two children would have a third child regardless of twinning). Same-sex children on average increase the sibling's probability of having a third child by $5.3 \%$.

While there is exactly a $50 \%$ chance of having two children of the same sex, a twin birth is far less common. About $1 \%$ of all the second births in our sample are twin births. The share is increasing slightly with time, reflecting the increasing prevalence of fertility treatment as well as increasing maternal age.

By using twinning at second birth as an IV, we capture the effect of a third child for parents who would otherwise have had only two children. Because twin births have zero spacing between the second and third child, they potentially capture a more straining experience than the average third birth. In contrast, the additional births induced by the same-sex instrument are intended and wanted, and they do not deviate systematically from the average third birth in terms of spacing.

In theory, the effect of a sibling's family increase could be recursive or self-reinforcing: Ego may respond to the sibling's third birth by increasing his or her own family size, in turn inducing the sibling to have a fourth child, which could again affect ego's family size. Such 'feedback effects' would be a mechanism for the effect of a sibling's third birth, rather than a threat to its identification. Given the low rates of parity progression beyond the third child, we consider such feedback effects unlikely to be a causal channel of importance for the effects we may find.

Of the two instruments, twinning has larger issues concerning internal validity. The likelihood of having dizygotic twins is positively correlated between sisters for genetic reasons and could therefore give rise to a spurious positive relationship in sisters' family size, causing estimates in pairs of sisters to be biased upwards. On the other hand, downward bias could be caused by the positive relationship between twinning and IVF treatment, which is a marker of subfecundity that is potentially shared by siblings - also of different sex. We test how twinning is related to observable characteristics and find that once we condition on the parents' (i.e., the sibling's and the sibling's partner's) age and spacing between births, twinning is not related to characteristics such as education, income, and fertility among other members of the family. Nevertheless, we cannot be completely certain that there is no bias resulting from unobservable characteristics. In addition, the low prevalence of twinning hampers the precision of the IV estimates. We place more trust in the results using the sex composition instrument, and we emphasise these if the results from the two instruments differ. 
Our main outcome variable is ego's number of children, measured ten (T10) years after the sibling had a second child (descriptive statistics in Table 1). While the twin instrument increases family size immediately, the same-sex instrument increases the probability of a third birth, taking place on average two to three years after the second one. If the IV is valid, there should be no (sizeable) effect on the outcome before the sibling's second child is born. We find no effect on ego's fertility five years before (T-5) the sibling's second child is born (nor on ego's fertility the same year as the sibling's second birth, available upon request).

For all outcomes and subsamples, we present three types of estimates: Reduced form (RF) estimates give the overall association in the sample between the sibling having twins or same-sex children and ego's number of children. IV estimates give the effect of the sibling's family size increase on ego's family size, under the assumption that the IVs affect ego's family size only through a change in the sibling's family size. Finally, OLS estimates give the conditional association between the sibling having a third child and ego's family size.

The register data used in this article cover the whole Norwegian population. We present significance tests to assess whether the relationships are plausibly driven by causal mechanisms that could also operate in comparable contexts, rather than appearing in this particular population due to mere chance (see Morgan and Winship (2007) for a general discussion of inference from a population to a (theoretical) super population in causal analysis).

Table 1: Descriptive statistics on outcome variables by subsample

\begin{tabular}{lccccccccc}
\hline & \multicolumn{4}{c}{ Men } & \multicolumn{4}{c}{ Women } \\
& \multicolumn{2}{c}{ Firstborn } & \multicolumn{2}{c}{ Secondborn } & \multicolumn{2}{c}{ Firstborn } & \multicolumn{2}{c}{ Secondborn } \\
& Mean & SD & Mean & SD & Mean & SD & Mean & SD \\
\hline N. children at T+10 & 1.82 & $(1.18)$ & 1.46 & $(1.16)$ & 2.08 & $(1.07)$ & 1.83 & $(1.08)$ \\
N. children at T-5 & 0.56 & $(0.84)$ & 0.14 & $(0.45)$ & 0.94 & $(0.97)$ & 0.29 & $(0.63)$ \\
\hline
\end{tabular}

Note: The sample is Norwegian firstborn and secondborn men and women whose sibling had a second child during the period 1980-1999.

\section{Results}

\subsection{Descriptive statistics and balancing tests}

Table 2 gives the mean values (and standard deviations) of background characteristics that are included in all our regressions, split by whether the index person has a sibling with same-sex children or not (panel A), and a sibling with twins at second birth or not 
Hart \& Cools: Identifying interaction effects using random fertility shocks

(panel B). For the same-sex instrument, we do not expect differences between the samples. The t-tests in the last column show that they hardly differ significantly - and never substantially. Twin births, however, are known to be random only when conditioning on parents' age (Black, Devereux, and Salvanes 2005). Panel B shows that parents of twins are on average a year older than parents with singleton births. They have also waited longer after their first birth - possibly due to fertility problems. The twin births in our sample on average take place about a year later than the other second births, reflecting that twinning has become more common over time.

Table 2: $\quad$ Background characteristics by instrument status

\begin{tabular}{lrrrrrr}
\hline & \multicolumn{2}{c}{ Z $=$ 0 } & \multicolumn{2}{c}{ Z $=\mathbf{1}$} & \multicolumn{2}{c}{ t-test } \\
& Mean & SD & Mean & SD & Diff. & SE \\
\hline a) Instrument $Z$ is same-sex & & & & & & \\
Ego's birth year & 1963.26 & $(5.85)$ & 1963.29 & $(5.83)$ & -0.03 & $(0.02)$ \\
Distance ego and sibling & 2.81 & $(1.51)$ & 2.82 & $(1.51)$ & $-0.01^{*}$ & $(0.01)$ \\
Sibling's age at 2nd birth & 28.63 & $(4.01)$ & 28.61 & $(4.00)$ & 0.02 & $(0.02)$ \\
Sibling's partner's age at 2nd birth & 29.40 & $(4.55)$ & 29.36 & $(4.56)$ & $0.04^{*}$ & $(0.02)$ \\
Sibling's spacing 1st and 2nd child & 3.31 & $(1.78)$ & 3.31 & $(1.78)$ & 0.01 & $(0.01)$ \\
Birth year sibling's 2nd child & 1991.52 & $(5.26)$ & 1991.52 & $(5.26)$ & 0.01 & $(0.02)$ \\
\hline b) Instrument $Z$ is twin2 & & & & & & \\
Ego's birth year & & & & & & \\
Distance ego and sibling & 1963.27 & $(5.84)$ & 1963.15 & $(5.64)$ & 0.12 & $(0.10)$ \\
Sibling's age at 2nd birth & 2.82 & $(1.51)$ & 2.85 & $(1.49)$ & -0.03 & $(0.03)$ \\
Sibling's partner's age at 2nd birth & 28.62 & $(4.00)$ & 29.64 & $(4.23)$ & $-1.02^{* *}$ & $(0.07)$ \\
Sibling's spacing 1st and 2nd child & 29.38 & $(4.55)$ & 30.37 & $(4.85)$ & $-0.99^{* *}$ & $(0.08)$ \\
Birth year sibling's 2nd child & 3.31 & $(1.78)$ & 3.65 & $(2.19)$ & $-0.34^{* *}$ & $(0.03)$ \\
\hline
\end{tabular}

Note: The sample is Norwegian firstborn and secondborn men and women whose sibling had a second child during the period $1980-1999 .{ }^{\dagger} p<0.10,{ }^{\star} p<0.05,{ }^{* *} p<0.01$.

The statistics displayed in Table 2 typically serve as 'balancing checks,' to see whether the IVs are indeed randomly allocated. Since twinning is only conditionally random, we have (in Table 3) estimated how the IVs predict a number of other background characteristics, observed the year prior to the birth of the sibling's second child (T-1): The sibling's schooling and income and ego's schooling, income, and number of children. If the instruments are unconditionally independent, no significant associations should be found. Under conditional independence, any significant associations should disappear after controlling for all the background characteristics in Table 2.

For the same-sex instrument, there are no significant associations beyond what is expected by chance. The twin instrument is however significantly associated with the outcomes in Table 3, but the association disappears when controls are included in column 4. 
Table 3: $\quad$ Balancing tests: Unconditional and conditional dependence on IVs

\begin{tabular}{lcccc}
\hline & \multicolumn{2}{c}{$Z$ is same-sex } & \multicolumn{2}{c}{$Z$ is twin2 } \\
& $\mathbf{( 1 )}$ & $\mathbf{( 2 )}$ & $\mathbf{( 3 )}$ & $\mathbf{( 4 )}$ \\
\hline Sib schoolyears T-1 & -0.016 & -0.010 & $0.154^{* *}$ & -0.018 \\
& $(0.011)$ & $(0.010)$ & $(0.051)$ & $(0.047)$ \\
Sib income T-1 & -93.559 & -63.637 & $14,117.119^{* *}$ & 471.436 \\
& $(454.920)$ & $(371.646)$ & $(2,049.190)$ & $(1,675.586)$ \\
Ego schoolyears T-1 & 0.014 & $0.018^{\dagger}$ & $0.119^{\star}$ & -0.005 \\
& $(0.011)$ & $(0.011)$ & $(0.050)$ & $(0.048)$ \\
Ego income T-1 & -712.241 & -475.395 & $10,759.499^{* *}$ & -984.921 \\
& $(457.407)$ & $(411.208)$ & $(2,062.250)$ & $(1,855.599)$ \\
Ego n. children T-1 & 0.004 & 0.006 & $0.077^{* *}$ & -0.005 \\
& $(0.004)$ & $(0.004)$ & $(0.018)$ & $(0.017)$ \\
\hline Table 2 covariates & No & Yes & No & \multicolumn{3}{c}{ Yes } \\
\hline
\end{tabular}

Note: The sample is Norwegian firstborn and secondborn men and women whose sibling had a second child during the period 1980-1999. Standard errors in parentheses. ${ }^{\dagger} p<0.10,{ }^{*} p<0.05,{ }^{* *} p<0.01$. "Table 2 covariates" indicates that the background characteristics shown in Table 2 are controlled for in columns (2) and (4).

\subsection{Sibship sex composition as IV}

Table 4 shows the effect of a sibling's number of children, instrumented by sex composition, on ego's number of children, measured ten (T10) years after the sibling's second birth. We present effects separately by sex and parity, allowing for heterogenous effects. Splitting by parity also ensures that the same individual cannot be both influenced and influencing (both ego and sibling) in the same statistical model, which would otherwise cause reflection bias (Angrist 2014). 
Hart \& Cools: Identifying interaction effects using random fertility shocks

Table 4: $\quad$ Effects of sibling's number of children on ego's family size (same-sex IV)

\begin{tabular}{|c|c|c|c|c|c|c|}
\hline \multirow{3}{*}{ Men } & \multicolumn{3}{|c|}{ Firstborns } & \multicolumn{3}{|c|}{ Secondborns } \\
\hline & (1) & (2) & (3) & (4) & (5) & (6) \\
\hline & RF & IV & OLS & RF & IV & OLS \\
\hline \multicolumn{7}{|c|}{ Ego's number of children at $T+10$} \\
\hline \multirow[t]{2}{*}{ Sib same-sex kids } & 0.014 & & & 0.002 & & \\
\hline & $(0.009)$ & & & $(0.008)$ & & \\
\hline \multirow[t]{2}{*}{ Sib $>2$ children } & & 0.227 & $0.112^{* *}$ & & 0.038 & $0.072^{* *}$ \\
\hline & & $(0.157)$ & $(0.010)$ & & $(0.158)$ & $(0.009)$ \\
\hline Adj. R2 & 0.017 & 0.016 & 0.019 & 0.074 & 0.074 & 0.074 \\
\hline $\mathrm{N}$ & 62231 & 62231 & 62243 & 75503 & 75503 & 75520 \\
\hline \multicolumn{7}{|c|}{ Ego's number of children at $T-5$} \\
\hline \multirow[t]{2}{*}{ Sib same-sex kids } & 0.004 & & & 0.002 & & \\
\hline & $(0.006)$ & & & $(0.003)$ & & \\
\hline \multirow[t]{2}{*}{ Sib $>2$ children } & & 0.070 & -0.009 & & 0.032 & $-0.011^{* *}$ \\
\hline & & $(0.099)$ & $(0.006)$ & & $(0.056)$ & $(0.003)$ \\
\hline Adj. R2 & 0.231 & 0.229 & 0.231 & 0.221 & 0.219 & 0.221 \\
\hline \multirow[t]{2}{*}{ N } & 62231 & 62231 & 62243 & 75503 & 75503 & 75520 \\
\hline & \multicolumn{3}{|c|}{ Firstborns } & \multicolumn{3}{|c|}{ Secondborns } \\
\hline \multirow[t]{2}{*}{ Women } & (1) & (2) & (3) & (4) & (5) & $(6)$ \\
\hline & RF & IV & OLS & RF & IV & OLS \\
\hline \multicolumn{7}{|c|}{ Ego's number of children at $T+10$} \\
\hline \multirow[t]{2}{*}{ Sib same-sex kids } & $0.018^{*}$ & & & 0.004 & & \\
\hline & $(0.009)$ & & & $(0.008)$ & & \\
\hline \multirow[t]{2}{*}{ Sib $>2$ children } & & $0.362^{*}$ & $0.124^{* *}$ & & 0.075 & $0.107^{* *}$ \\
\hline & & $(0.178)$ & $(0.009)$ & & $(0.148)$ & $(0.008)$ \\
\hline Adj. R2 & 0.002 & & 0.005 & 0.044 & 0.046 & 0.046 \\
\hline $\mathrm{N}$ & 57937 & 57937 & 57943 & 71521 & 71521 & 71541 \\
\hline \multicolumn{7}{|c|}{ Ego's number of children at $\mathbf{T}-5$} \\
\hline \multirow[t]{2}{*}{ Sib same-sex kids } & 0.003 & & & 0.000 & & \\
\hline & $(0.007)$ & & & $(0.004)$ & & \\
\hline \multirow[t]{2}{*}{ Sib $>2$ children } & & 0.064 & -0.000 & & 0.005 & $-0.014^{\star *}$ \\
\hline & & $(0.142)$ & $(0.008)$ & & $(0.075)$ & $(0.004)$ \\
\hline Adj. R2 & 0.221 & 0.220 & 0.221 & 0.279 & 0.279 & 0.279 \\
\hline $\mathrm{N}$ & 57937 & 57937 & 57943 & 71521 & 71521 & 71541 \\
\hline
\end{tabular}

Note: The sample is Norwegian firstborn and secondborn men and women whose sibling had a second child during the period 1980-1999. Standard errors in parentheses. ${ }^{\dagger} p<0.10,{ }^{*} p<0.05,{ }^{* *} p<0.01$.

For comparison, we also show the OLS estimate for how ego's fertility changes with the sibling's third child. On average across subsamples, a sibling's third child is 
associated with about a tenth of a child more for ego. This association is statistically significantly different from zero in all subsamples.

In general, neither the RF nor the IV estimates differ significantly from zero - with one exception: For firstborn women, there are significant positive effects $(p<.1)$. However, this point estimate is not statistically different from the corresponding point estimates in any of the other subgroups, hence the different results by subgroup should be interpreted with caution. Reassuringly, we find no evidence of significant effects prior to realization of the instrument (at $\mathrm{T}-5$ ).

The IV estimates do not differ significantly from the OLS estimates. Our IV estimates do not, therefore, provide evidence against the possibility that the association in siblings' fertility behavior, as captured by the OLS estimates, are due to interaction effects.

A zero effect on number of children after ten years could mask tempo effect or effects at specific parities (ego's propensity to have at least one, two, or three children). Using the same-sex IV, we find no statistically significant effect at any time or parity (results available upon request).

\subsection{Twinning as IV}

Table 5 shows estimates obtained by using the twin instrument. Across subsamples, the reduced form and IV estimates show no significant effect on ego's fertility. The point estimates tend to be positive, but we cannot refute the zero hypothesis that a sibling's family size has no effect on ego's fertility behavior.

When the outcome is measured prior to the sibling's second child is born ( $T-5)$, we find no significant effect, corroborating the (conditional) exogeneity of twinning as an IV.

As in the case with the same-sex IV, the absence of an effect on number of children after ten years could mask tempo-specific or parity-specific effects. We also find no statistically significant effect at any time on parity using the twin IV (results available upon request). 
Hart \& Cools: Identifying interaction effects using random fertility shocks

Table 5: $\quad$ Effects of sibling's number of children on ego's family size (Twin IV)

\begin{tabular}{|c|c|c|c|c|c|c|}
\hline \multirow{3}{*}{ Men } & \multicolumn{3}{|c|}{ Firstborns } & \multicolumn{3}{|c|}{ Secondborns } \\
\hline & (1) & (2) & (3) & (4) & (5) & (6) \\
\hline & RF & IV & OLS & RF & IV & OLS \\
\hline \multicolumn{7}{|c|}{ Ego's number of children at $T+\mathbf{1 0}$} \\
\hline \multirow[t]{2}{*}{ Sib twin 2nd birth } & 0.038 & & & -0.025 & & \\
\hline & $(0.043)$ & & & $(0.036)$ & & \\
\hline \multirow[t]{2}{*}{ Sib $>2$ children } & & 0.066 & $0.112^{* *}$ & & -0.044 & $0.072^{* *}$ \\
\hline & & $(0.076)$ & $(0.010)$ & & $(0.064)$ & $(0.009)$ \\
\hline Adj. R2 & 0.016 & 0.018 & 0.019 & 0.074 & 0.072 & 0.074 \\
\hline $\mathrm{N}$ & 62978 & 62978 & 62243 & 76471 & 76471 & 75520 \\
\hline \multicolumn{7}{|c|}{ Ego's number of children at T-5 } \\
\hline \multirow[t]{2}{*}{ Sib twin 2nd birth } & 0.014 & & & 0.009 & & \\
\hline & $(0.027)$ & & & $(0.013)$ & & \\
\hline \multirow[t]{2}{*}{ Sib $>2$ children } & & 0.024 & -0.009 & & 0.016 & $-0.011^{* \star}$ \\
\hline & & $(0.048)$ & $(0.006)$ & & $(0.023)$ & $(0.003)$ \\
\hline Adj. R2 & 0.231 & 0.231 & 0.231 & 0.222 & 0.221 & 0.221 \\
\hline \multirow[t]{2}{*}{ N } & 62978 & 62978 & 62243 & 76471 & 76471 & 75520 \\
\hline & \multicolumn{3}{|c|}{ Firstborns } & \multicolumn{3}{|c|}{ Secondborns } \\
\hline \multirow[t]{2}{*}{ Women } & (1) & (2) & (3) & (4) & (5) & $(6)$ \\
\hline & RF & IV & OLS & RF & IV & OLS \\
\hline \multicolumn{7}{|c|}{ Ego's number of children at $T+\mathbf{1 0}$} \\
\hline \multirow[t]{2}{*}{ Sib twin 2nd birth } & 0.014 & & & 0.004 & & \\
\hline & $(0.040)$ & & & $(0.035)$ & & \\
\hline \multirow[t]{2}{*}{ Sib $>2$ children } & & 0.025 & $0.124^{\star *}$ & & 0.007 & $0.107^{\star *}$ \\
\hline & & $(0.071)$ & $(0.009)$ & & $(0.061)$ & $(0.008)$ \\
\hline Adj. R2 & 0.002 & 0.003 & 0.005 & 0.044 & 0.044 & 0.046 \\
\hline$N$ & 58655 & 58655 & 57943 & 72432 & 72432 & 71541 \\
\hline \multicolumn{7}{|c|}{ Ego's number of children at $\mathrm{T}-5$} \\
\hline \multirow[t]{2}{*}{ Sib twin 2nd birth } & 0.016 & & & -0.001 & & \\
\hline & $(0.032)$ & & & $(0.018)$ & & \\
\hline \multirow[t]{2}{*}{ Sib $>2$ children } & & 0.027 & -0.000 & & -0.001 & $-0.014^{\star *}$ \\
\hline & & $(0.057)$ & $(0.008)$ & & $(0.031)$ & $(0.004)$ \\
\hline Adj. R2 & 0.221 & 0.221 & 0.221 & 0.279 & 0.279 & 0.279 \\
\hline$N$ & 58655 & 58655 & 57943 & 72432 & 72432 & 71541 \\
\hline
\end{tabular}

Note: The sample is Norwegian firstborn and secondborn men and women whose sibling had a second child during the period 1980-1999. Standard errors in parentheses. ${ }^{\dagger} p<0.10,{ }^{*} p<0.05,{ }^{* *} p<0.01$. 


\subsection{Subsample analysis}

Nonsignificant effects in the full sample could mask significant effects in subpopulations where transmission is particularly strong. To test if similarity fosters transmission (Bernardi and Klaerner 2014), we have estimated the models for siblings of the same sex. We find no evidence of particularly strong interaction effects among siblings of the same sex. The overall pattern is consistent across subgroups, with positive but insignificant point estimates (available upon request).

\section{Concluding discussion}

The importance of social networks for the transmission of information regarding the consequences of fertility choices has recently (re)emerged as a topic of demographic interest (Bernardi and Klaerner 2014). While there are indeed good reasons to expect, 'a priori,' that fertility is contagious within networks, remarkably few studies credibly address the difficulty in obtaining unbiased and consistent estimates of the causal effect.

Rather, in the sociodemographic and sociological literature on interaction effects, one traditionally allows for (potential) bias in order to gain precision: Correlated fertility behavior within networks can be estimated easily and precisely, given available data, and has been demonstrated for a variety of networks in a range of contexts (Balbo and Barban 2014; Lois and Becker 2014; Lyngstad and Prskawetz 2010; Kuziemko 2006; Pink, Leopold, and Engelhardt 2014). However, a main methodological point of the current paper is that such correlated behavior itself is not evidence of interaction effects. It may equally well emerge because individuals in the same network face a similar environment, or because they are similar on relevant unobservable characteristics - or it may even result from reflection bias (Manski 1995).

Our study contributes to the existing literature by using two well-established IVs for fertility that are increasingly important also in demographic research, applying them to the question of interaction effects in fertility. The two IVs have proven efficient in uncovering estimates of the effect of family size increases on a variety of outcomes, ranging from parents' labour market outcomes to older siblings' cognitive skills and their fertility choices in adulthood (see, e.g., Angrist and Evans 1998; Black, Devereux, and Salvanes 2010; Cools and Hart 2017). In contrast, the IV estimates of the fertility interaction effects between siblings obtained in this paper are generally not significantly different from zero. This holds both for measures of quantum and tempo, and both for number of children and parity-specific measures. While one could speculate that a sibling's third birth would have the strongest effects on ego's third birth, we find no evidence of this.

Subgroup analysis further show no evidence of stronger interaction effects between siblings of the same sex, thereby yielding no support for the notion that similarity strength- 
Hart \& Cools: Identifying interaction effects using random fertility shocks

ens influence in our context. Neither do younger siblings seem to be more strongly influenced by their older siblings than vice versa. On the contrary, coefficients are consistently less positive among secondborn men and women than among their older siblings. The only IV estimate of the fertility interaction effect between siblings that is significant at conventional levels is the one obtained for firstborn women when instrumenting their younger sibling's fertility with the same-sex instrument.

Some limitations are inherently linked to our quasi-experimental effect identification. Most importantly, while the internal validity of our estimates is strong, the external validity (i.e. relevance to other parities and contexts) is more uncertain. We demonstrate empirically that third births - like first births - are positively correlated across siblings in our sample. Previous research has focused predominantly on the transition to parenthood (cf. Balbo and Barban (2014); Bernardi (2003); Lyngstad and Prskawetz (2010)), and both empirical patterns and theoretical reasoning are better established for this parity. We argue in Section 2 that both social learning and emotional contagion is potentially important also for interaction effects from large families. Still, we acknowledge that these mechanisms may operate in a somewhat different - and perhaps also somewhat weaker - fashion for third than for first births. In the end, the relevance of our results for other parity transitions is an empirical question. Our results call for studies utilizing sources of plausibly exogenous variation in (the timing of) first births to test if interaction effects can be identified in a causal design at this parity.

The second limitation regards the trade-off between consistency and precision, which is evident also in our study. The IV estimates are not significantly different from the OLS estimates of associations in fertility between siblings presented. Yet this paper challenges the notion that network associations in fertility can be interpreted as network effects without stronger evidence. While the associations within the network are strong and highly significant, we fail to provide conclusive evidence that they are due to (social) network effects.

Despite their limitations, our results reactualize Manski's (1995) point that similarity in networks is insufficient evidence that social interaction effects indeed occur. Siblings may also simply behave in lockstep because they or their circumstances are similar. There is not enough credible evidence on whether siblings affect each other's fertility. The results of this study emphasise the need for further empirical tests of whether within-network associations in fertility are indeed driven by within-network causal effects. Through such tests we can advance our theorizing and understanding of the drivers of network similarities in fertility. 


\section{References}

Abajobir, A., Maravilla, J., Alati, R., and Najman, J.M. (2016). A systematic review and meta-analysis of the association between unintended pregnancy and perinatal depression. Journal of Affective Disorders 192: 56-63. doi:10.1016/j.jad.2015.12.008.

Angrist, J. (2014). The perils of peer effects. Labour Economics 30: 98-108. doi:10. 1016/j.labeco.2014.05.008.

Angrist, J. and Evans, W. (1998). Children and their parents' labor supply: Evidence from exogenous variation in family size. The American Economic Review 88(3): 450-477.

Balbo, N. and Barban, N. (2014). Does fertility behavior spread among friends? American Sociological Review 79(3): 412-431. doi:10.1177/0003122414531596.

Barber, J. and East, P. (2009). Home and parenting resources available to siblings depending on their birth intention status. Child Development 80(3): 921-939. doi:10.1111/ j.1467-8624.2009.01306.x.

Bergsvik, J., Lappegård, T., and Skardhamar, T. (2016). Spatial variations in family size and the neighbor's role for transition to third birth. Paper presented at the Annual Meeting of the Population Association America, Washington, D.C., USA, March 31April 2, 2016.

Bernardi, L. (2003). Channels of social influence on reproduction. Population Research and Policy Review 22(5-6): 427-555. doi:10.1023/B:POPU.0000020892.15221.44.

Bernardi, L. and Klaerner, A. (2014). Social networks and fertility. Demographic Research 33(22): 641-670. doi:10.4054/DemRes.2014.30.22.

Black, S., Devereux, P., and Salvanes, K. (2005). The more the merrier? The effect of family size and birth order on children's education. The Quarterly Journal of Economics 120(2): 669-700.

Black, S., Devereux, P., and Salvanes, K. (2010). Small family, smart family? family size and the iq scores of young men. Journal of Human Resources 45(1): 33-58.

Cáceres-Delpiano, J. and Simonsen, M. (2012). The toll of fertility on mothers' wellbeing. Journal of Health Economics 31(5): 752-766. doi:10.1016/j.jhealeco.2012. 05.006 .

Cools, S. and Hart, R. (2017). The effect of sibship size on fertility in adulthood: New evidence from IV estimation. Demography 53(1): 23-44. doi:10.1007/s13524-0160537-z.

Cools, S., Markussen, S., and Strøm, M. (2017). Children and careers: How family size affects parents' labor market outcomes in the long run. Demography 54(5): 1773- 
Hart \& Cools: Identifying interaction effects using random fertility shocks

1793. doi:10.1007/s13524-017-0612-0.

Cools, S. and Strøm, M. (2017). Parenthood wage penalties in a double income society. Review of Economics of the Household 14(2): 391-416. doi:10.1007/s11150-0149244-y.

Cools, S. and Strøm, M. (2018). Mellom arbeidsliv og familieliv: Hvilken betydning har arbeidsmarkedssituasjonen for om menn og kvinner velger å få barn? [Between family life and work life: how does the labor market matter for childbearing decisions?]. Oslo: Institute for Social Research (Rapport 2018:13).

Dahl, G., Løken, K., and Mogstad, M. (2014). Peer effects in program participation. American Economic Review 104(7): 2049-2074. doi:10.1257/aer.104.7.2049.

David, H. (2006). Born unwanted, 35 years later: The Prague study. Reproductive Health Matters 14(27): 181-190. doi:10.1016/S0968-8080(06)27219-7.

Dommermuth, L. and Lappegård, T. (2017). Nedgangen i fruktbarheten fra 2010: Betydningen av utdanning, $\varnothing$ konomisk aktivitet og $\varnothing$ konomiske ressurser for førstef $\varnothing \mathrm{dsler}$ og tredjefødsler [The decline in fertility from 2010: The importance of education, economic activity and economic resources for first and third births]. Oslo: Statistics Norway (Rapporter 2017/12).

Fiori, F., Graham, E., and Feng, Z. (2014). Geographical variations in fertility and transition to second and third birth in Britain. Advances in Life Course Research 21: 149167. doi:10.1016/j.alcr.2013.11.004.

Gini, C. (2014). Combinations and sequences of sexes in human families and mammal litters. Acta Genetica et Statistica Medica 2(3): 220-244. doi:10.1017/ S0016672300015834.

Gray, E. and Evans, A. (2014). Geographic variation in parity progression in Australia. Population, Space and Place 24(2): e2080. doi:10.1002/psp.2080.

Kolk, M. (2015). The causal effect of an additional sibling on completed fertility: An estimation of intergenerational fertiliy correlations by looking at siblings of twins. Demographic Research 32(51): 1409-1420. doi:10.4054/DemRes.2015.32.51.

Kotte, M. and Ludwig, V. (2011). Intergenerational transmission of fertility intentions and behaviour in Germany: The role of contagion. Vienna Yearbook of Population Research 9: 207-226. doi:10.1553/populationyearbook2011s207.

Kravdal, (1992). The weak impact of female labour force participation on norwegian third-birth rates. European Journal of Population 8(3): 247-263. doi:10.4054/ DemRes.2014.30.22.

Kruk, K. and Reinhold, S. (2014). The effect of children on depression in old age. Social 
Science and Medicine 100: 1-11. doi:10.1016/j.socscimed.2013.09.003.

Kuziemko, I. (2006). Is having babies contagious? Estimating fertility peer effects between siblings. Princeton: Princeton University (Technical report).

Lois, D. and Becker, O. (2014). Is fertility contagious? Using panel data to disentangle mechanisms of social network influences on fertility decisions. Advances in Life Course Research 21: 123-134. doi:10.1016/j.alcr.2013.10.001.

Lyngstad, T. and Noack, T. (2005). Vil de velge bort familien? En studie av unge nordmenns fruktbarhets-og ekteskapsintensjoner [Will they forgo the family? An analysis of young Norwegian's fertility and marriage intentions]. Tidsskrift for Velferdsforskning 8: 120-134.

Lyngstad, T. and Prskawetz, A. (2010). Do siblings' fertility decisions influence each other? Demography 47(4): 923-934. doi:10.1007/BF03213733.

Manski, C. (1995). Identification problems in the social sciences. Cambridge: Harvard University Press.

Monstad, K., Propper, C., and Salvanes, K. (2011). Is teenage motherhood contagious? Evidence from a natural experiment. Washington, D.C.: Centre for Economic Policy Research (CEPR Discussion Paper No. DP8505).

Morgan, S. and Winship, C. (2007). Counterfactuals and causal inference: Methods and principles for social research. Cambridge: Cambridge University Press.

Myhrman, A., Olsen, P., Rantakallio, P., and Laara, E. (1995). Does the wantedness of a pregnancy predict a child's educational attainment? Family Planning Perspectives 27: 116-119. doi:10.2307/2136109.

Pink, S., Leopold, T., and Engelhardt, H. (2014). Fertility and social interaction at the workplace: Does childbearing spread among colleagues? Advances in Life Course Research 21: 113-122. doi:10.1016/j.alcr.2013.12.001.

Rønsen, M. (2004). Fertility and family policy in Norway: A reflection on trends and possible connections. Demographic Research 10(10): 265-286. doi:10.4054/DemRes. 2004.10.10.

Rosenzweig, M. and Wolpin, K. (1980a). Life-cycle labor supply and fertility: Causal inferences from household models. The Journal of Political Economy 88(2): 328-348. doi:10.1086/260868.

Rosenzweig, M. and Wolpin, K. (1980b). Testing the quantity-quality fertility model: The use of twins as a natural experiment. Econometrica: Journal of the Econometric Society 48(1): 227-240. doi:10.2307/1912026. 
Hart \& Cools: Identifying interaction effects using random fertility shocks

Rotkirch, A. (2007). All that she wants is a(nother) baby? Longing for children as a fertility incentive of growing importance. Journal of Evolutionary Psychology 5(1): 89-104. doi:10.1556/JEP.2007.1010.

Yakusheva, O. and Fletcher, J. (2015). Learning from teen childbearing experiences of close friends: Evidence using miscarriages as a natural experiment. Review of Economics and Statistics 97(1): 29-43. doi:10.1162/REST_a_00423. 